\title{
PROPERTIES OF THE HIGH BURNUP STRUCTURE IN NUCLEAR LIGHT WATER REACTOR FUEL
}

\author{
T. WISS ${ }^{1}$, V.V. RONDINELLA ${ }^{1}$, R.J.M. KONINGS ${ }^{1}$, D. STAICU ${ }^{1}$, D. PAPAIOANNOU ${ }^{1}$, S. BREMIER ${ }^{1}$, P. \\ PÖML $^{1}$, O. BENES ${ }^{1}$, J.-Y. COLLE ${ }^{1}$, P. VAN UFFELEN ${ }^{1}$, A. SCHUBERT ${ }^{1}$, F. CAPPIA ${ }^{1}$, M. MARCHETTI ${ }^{1}$, D. \\ PIZZOCRI ${ }^{2}$, F. JATUFF ${ }^{3}$, W. GOLLL ${ }^{4}$, T. SONODA ${ }^{5}$, A. SASAHARA ${ }^{5}$, S. KITAJIMA ${ }^{5}$, M. KINOSHITA ${ }^{5}$ \\ ${ }^{1}$ European Commission, Joint Research Centre, Directorate Nuclear Safety and Security, P.O. box \\ 2340, 76125 Karlsruhe, Germany \\ ${ }^{2}$ Politecnico di Milano, Department of Energy, Nuclear Engineering Division, Via La Masa 34, 20156, \\ Milan, Italy \\ ${ }^{3}$ Kernkraftwerk Gösgen-Däniken AG, P.O. Box, 4658 Däniken, Switzerland \\ ${ }^{4}$ AREVA-NP GmbH, Freyeslebenstrasse 1, 91058 Erlangen, Germany \\ ${ }^{5}$ CRIEPI, Japan, 2-11-1 Iwado-Kita, Komae-Shi, Tokyo 201-8511, Japan
}

\section{Abstract}

The formation of the RIM- or High Burnup Structure (HBS) is possibly the most significant example of the restructuring processes affecting commercial nuclear fuel in-pile. The HBS forms at the relatively cold outer rim of the fuel pellet, where the local burnup is 2-3 times higher than the average pellet burnup, under the combined effects of irradiation and thermo-mechanical conditions determined by the power regime and the fuel rod configuration. The main features of the transformation are the subdivision of the original fuel grains into new sub-micron grains, the relocation of the fission gas into newly formed intergranular pores, and the absence of large concentrations of extended defects in the fuel matrix inside the subdivided grains. The characterization of the newly formed structure and its impact on thermo-physical or mechanical properties is a key requirement to ensure that high burnup fuel operates within the safety margins. This paper presents a synthesis of the main findings from extensive studies performed at JRC-ITU during the last 25 years to determine properties and behaviour of the HBS. In particular, microstructural features, thermal transport, fission gas behaviour, and thermo-mechanical properties of the HBS will be discussed. The main conclusion of the experimental campaigns is that the HBS does not compromise the safety of nuclear fuel during normal operations.

Keywords: High Burnup Structure, LWR Fuel, thermal transport, thermo-mechanical properties, gas release, microstructure 



\section{INTRODUCTION}

Extension of the authorised burnup of light water reactor (LWR) fuel is an important issue for nuclear reactor operation. The benefits of increased fuel burnup are a decrease in the volume of spent fuel discharged and fuel cycles cost. It also leads to less refuelling operations and thus higher availability. With the increase of the burnup, it has become important to establish the practical limitations that may arise from the physical evolution of the fuel, with the basically postulated limitation being the restructuring of the $\mathrm{UO}_{2}$ fuel that occurs at the pellet periphery in high burnup LWR fuel. This restructuring was observed for the first time in very high burnup fuel in the late 1950s as described by Belle ${ }^{1}$. It is generally called the high-burnup structure (HBS) or rim structure. This structure starts to form when the local burnup exceeds about $60 \mathrm{GWd} \cdot \mathrm{t}^{-1}$. The formation of the HBS is characterised by four consecutive phases: sub-division of the original grains by polygonisation, loss of xenon from the new grain structure, formation of micrometer sized pores in the re-crystallized new structure as a result of diffusion of fission gas out of the new grain structure, growth of the new pores with increase in the local burnup as they collect the gas that continuously flow from the surrounding re-crystallised grains.

The HBS has been extensively investigated for almost 25 years and many properties and characteristics of this structure have been measured, including microstructure changes, fission gas release and xenon depletion, porosity, thermal conductivity, oxidation state, and lattice parameter ${ }^{2-}$

${ }^{10}$. But there are still some discussions about this high burnup structure formation processes ${ }^{11}$ and its behaviour in accidental condition, which is the purpose of the current paper to present.

\section{MICROSTRUCTURE}

\subsection{MICROSCOPY}

At average burnups above about $45 \mathrm{GWd} \cdot \mathrm{t}^{-1}$, a porous outer ring is formed in nuclear $\mathrm{UO}_{2}$ fuels with a typical thickness of 100 to $200 \mu \mathrm{m}$ (which corresponds to $4-8 \%$ of the fuel volume) ${ }^{12}$. In this region, the local bumup is largely increased by a factor 2-3 due to Pu-formation by resonance absorption of neutrons ${ }^{13}$.

The new structure, today called High Burnup Structure (HBS) is more precisely characterized by grain subdivision and redistribution of fission gases and extended defects. The original grains, with a typical size of around $10 \mu \mathrm{m}$, subdivide by a factor of 104 into sub-micron grains with a size of about $0.1-0.3 \mu \mathrm{m}$. The fission gas is removed from the fuel matrix, and is retained in a high concentration of micron-sized intergranular closed pores; reported values for the porosity fraction in the HBS can exceed $20 \%{ }^{14}$. The microstructure of the subdivided grains appears free of extended defects as will be shown below. 
From the ceramographies shown in Fig. 1, from fuel irradiated within a broad range of burnups and temperatures it can be clearly seen that an extensive porosity forms at a burnup and temperature threshold which has also been unambiguously confirmed by the scanning electron microscopy (SEM) images shown in Fig. 2. These thresholds lay around $70 \mathrm{GWd} \cdot \mathrm{t}^{-1}$ for the burnup and $\sim 1100{ }^{\circ} \mathrm{C}$ for the irradiation temperature respectively. The discrete irradiation conditions do not allow more refined values at the time.

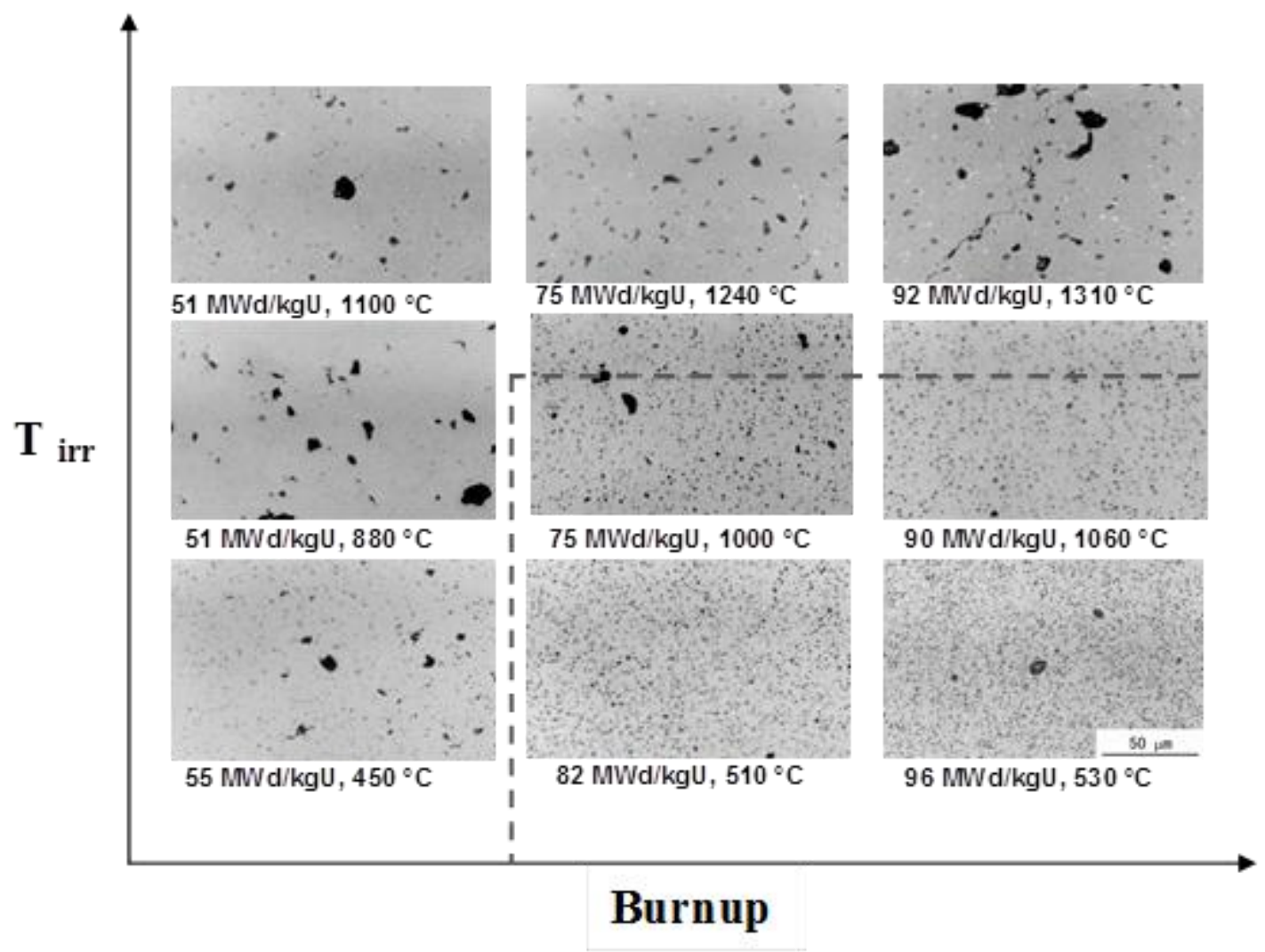

FIG. 1. Ceramographies of a series of samples irradiated in a matrix of burnup and temperature range in the frame of the HBRP program ${ }^{2}$. The dashed line indicates the threshold temperature and burnup for the HBS formation (lower right corner) as evidenced from the increase in porosity.

Fig. 2 shows the typical SEM images in the test matrix of burnup and temperature. Before restructuring, most of the specimen has a structure characterized by original grains whose average size is $\sim 10 \mu \mathrm{m}$. After restructuring, small divided grains with size ranging between $100 \mathrm{~nm}$ and $2 \mu \mathrm{m}$ are observed. 


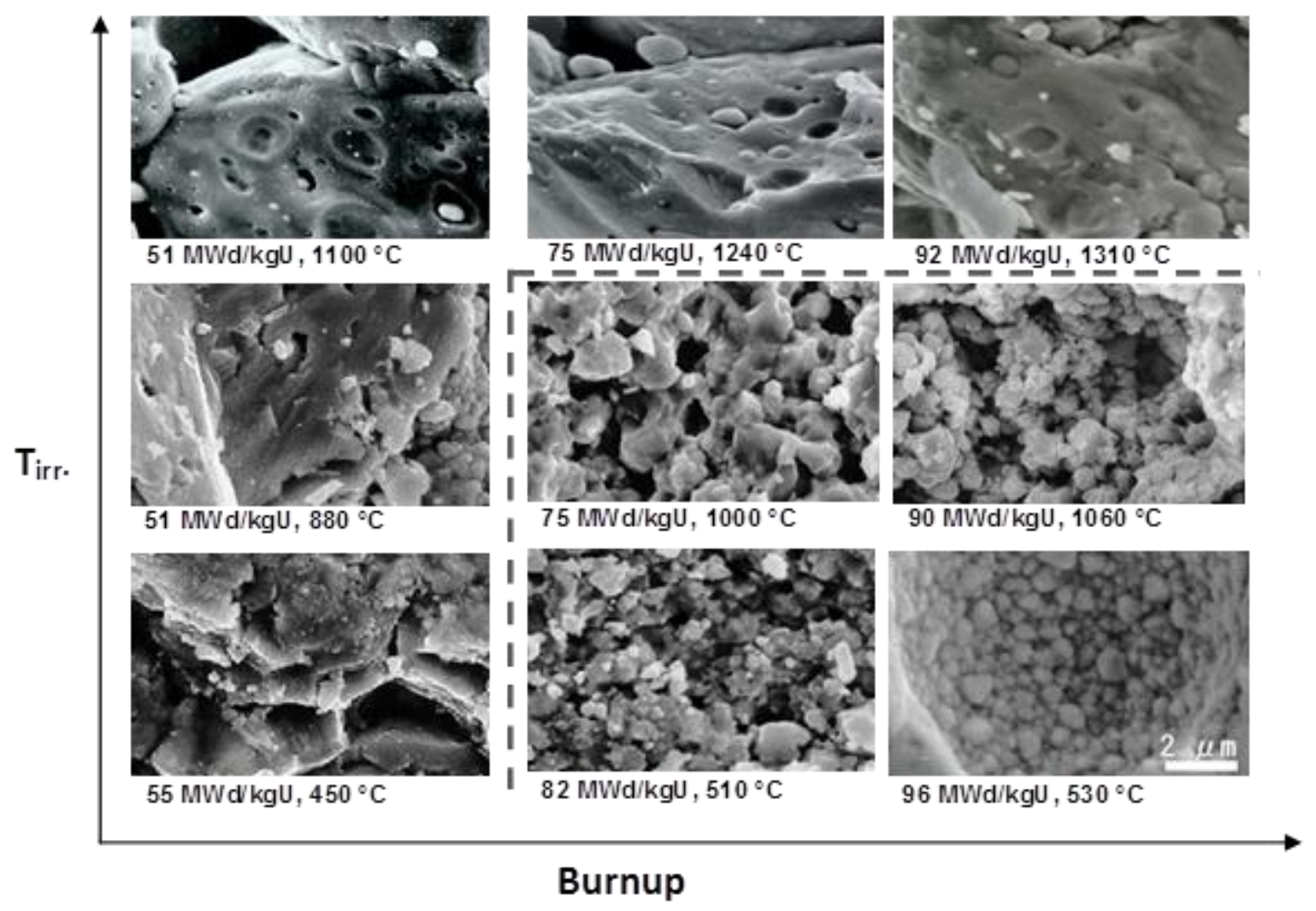

FIG. 2. SEM observations on the fracture surfaces of specimens irradiated at different burnups and temperatures. All pictures have the same magnification. The dashed line shows the threshold for the HBS formation (lower right corner).

The restructured region extends from the pellet edge inwards along the pellet radius. Recently, qualitative appreciation of the extent of restructuring along the radius has been performed on a $\mathrm{UO}_{2}$ cross section with $\approx 80 \mathrm{GWd} . \mathrm{t}^{-1}$ average pellet burnup. The grain morphology evolution is illustrated in Fig. $3(\mathrm{a})$-(f), corresponding to different radial locations ${ }^{15,16}$. This specimen was characterized by the presence of a cavity running along the radius, so the images do not show polished or fracture surfaces, but rather "free" inner cavity surfaces. In the first micrograph (Fig. 3a), corresponding to the centre of the pellet, the original grain morphology, decorated on the grain boundaries with a number of metallic fission products precipitates, is evident. Already at radial positions $\mathrm{r} / \mathrm{r} 0 \approx 0.30$, grooves start to appear on the surface of the original grains (Fig. 3b). The amount of grain surface affected by the groove formation increases while proceeding towards the pellet periphery (Figs. 3c and $3 \mathrm{~d}$ ) till extensive restructuring, including grain subdivision, and a substantial loss of the original grain contour are evident (Fig. 3e). No large pore family is visible here; this may be partly due to the fact this is not a fracture surface: the presence of pores or openings would indicate substantial fission gas release and would be expected at higher irradiation temperatures ${ }^{16}$. Finally, at the outermost periphery (Fig. 3f), the typical features which characterize the HBS are present: micrometric intergranular pores and submicrometric grains. 

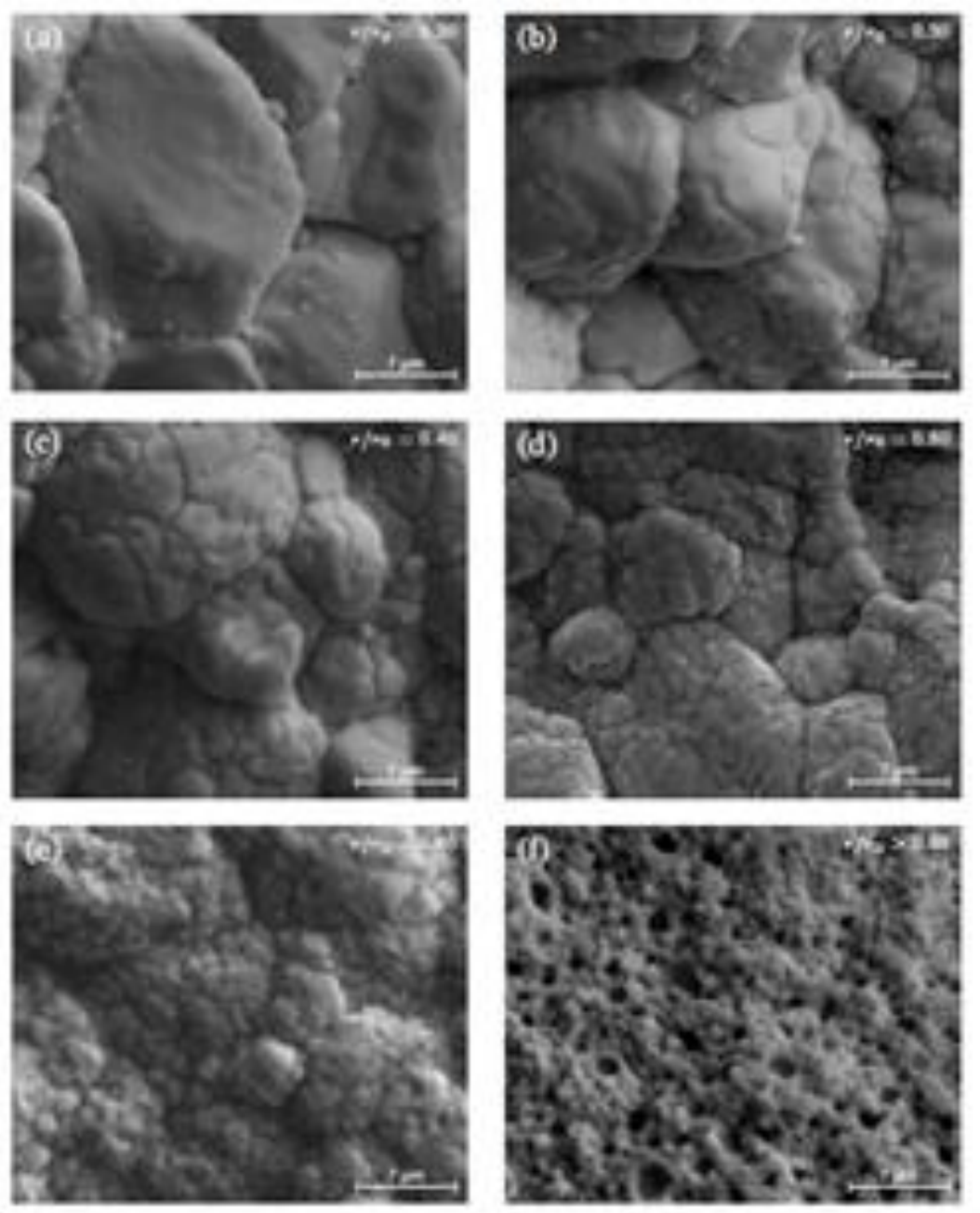

Figure 3: (a)-(f) SEM images of the sample with average burnup $80 \mathrm{GWd} \cdot \mathrm{t}^{-1}$ showing the grain structure in a cavity cutting through the pellet radius.

More in detail, two structures, rounded grains at open surfaces and (bulk) polyhedral grains, have been identified in the high-burnup region of the fuel ${ }^{17}$. In one of his papers ${ }^{12}$ Matzke has introduced the term "cauliflower" structure to describe the appearance of the fuel, other authors have named the phenomenon the "rim effect". The formation of smaller grains at open surfaces (e.g. pores) shows a fractal appearance with the smaller grains having a size of less than $10 \mathrm{~nm}$ as can be seen in Fig. 4 on the 3 SEM micrographs. The determined fractal dimension was 2.2, thus very close to the one of the cauliflower as the HBS was earlier referred to ${ }^{12}$. The surface reorganization has been observed by scanning electron microscopy ${ }^{12,18}$ and is accompanied by a bulk restructuring that is also observable by scanning electron microscopy (see Figure 2) but is mostly investigated by transmission electron microscopy $(\text { TEM })^{19,20}$. The fuel transforms by a sub-division process in polyhedral grains surrounding pores. The newly formed tiny grains are often found to be slightly disoriented (a few 
degrees $)^{20}$. A more recent observation of a memory effect of the original grains structure supports this assumption ${ }^{9}$.
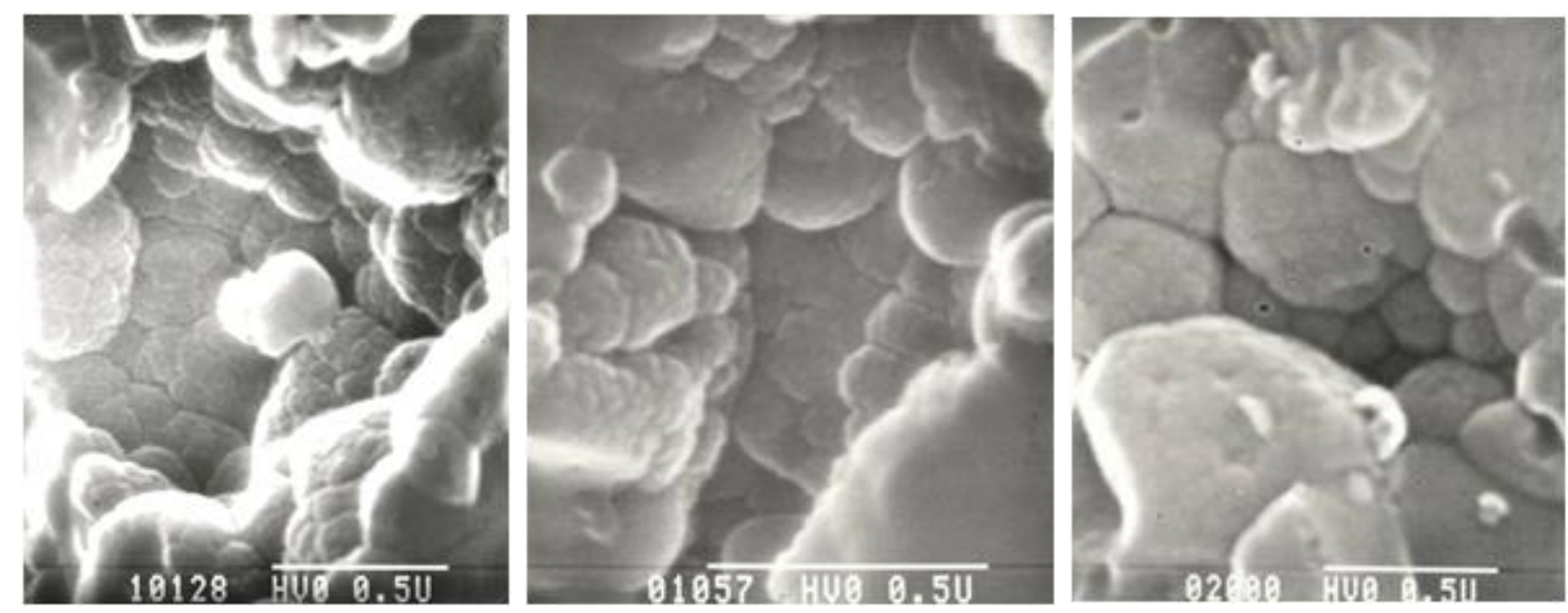

FIG. 4.secondary electron images showing the restructured pattern inside a pore of the HBS. The fractal aspect can be noted at the different magnifications

More evidence of the restructuring can be visualized from TEM investigations $s^{5,7,20-22}$. The resolution of the instrument allows observing nanometer sized features such as five metal precipitates, nanobubbles, dislocations (lines, loops), etc. It is not intended to detail the various microstructural aspects here but there is a clear difference between regular grains and re-structured grains providing they differ only from the burnup point of view. 


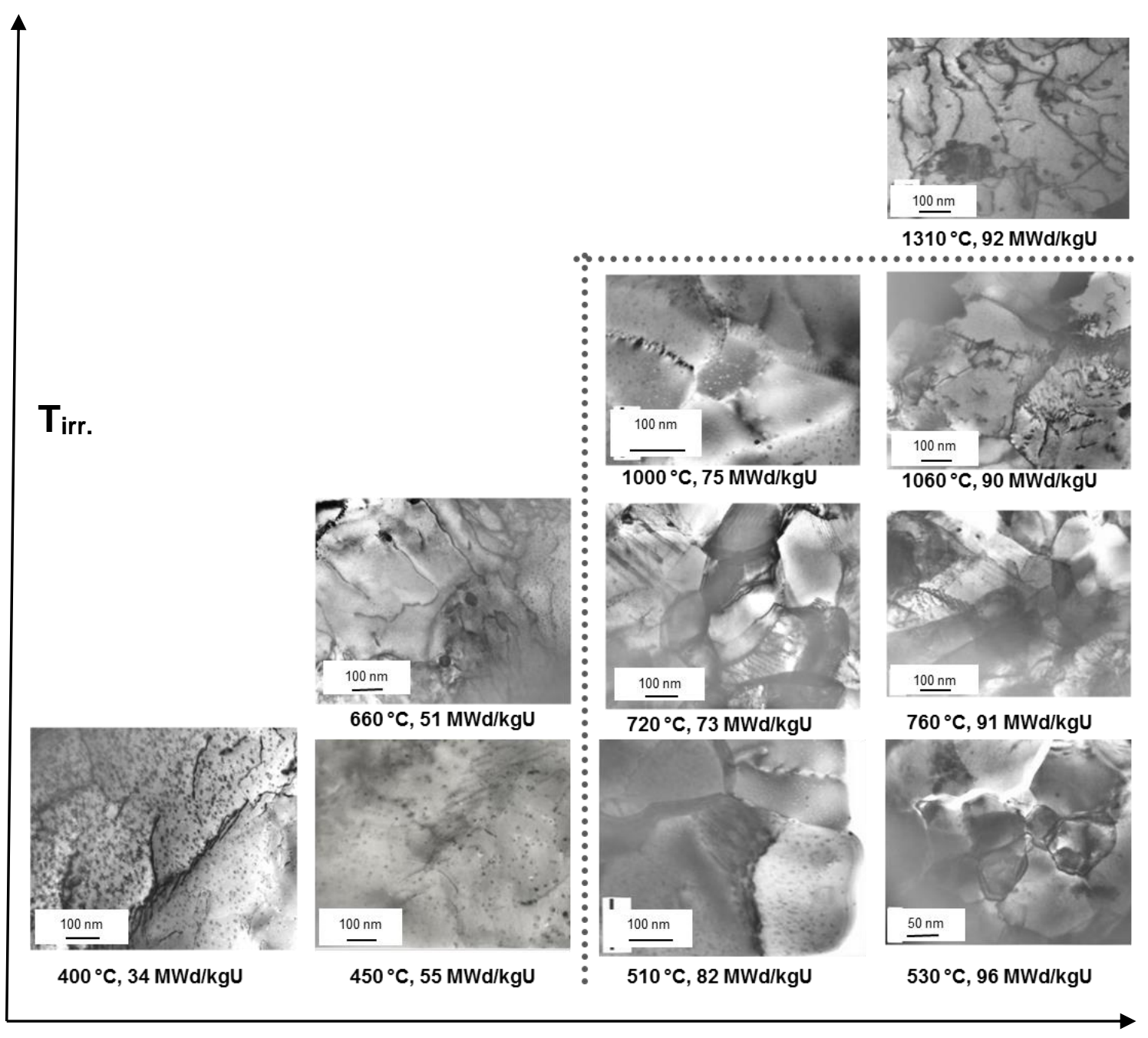

\section{Burnup}

FIG. 5. Series of TEM bright field micrographs showing the microstructure evolution as a function of the irradiation conditions (burnup, temperature). These images have been acquired in the frame of the HBRP program ${ }^{2}$. The small restructured grains are clearly visible in the lower right corner below the dashed line indicating the threshold for the HBS formation.

In the TEM micrographs of Fig. 5 the burnup and temperature threshold for the HBS formation are clearly seen if one accepts the formation of the $\sim 200 \mathrm{~nm}$ size grains as a significant result of restructuring of the original $\sim 10 \mu \mathrm{m}$ size grains. More specifically, the images of the samples irradiated below $55 \mathrm{GWd} \cdot \mathrm{t}^{-1}$ show that no re-structuring occurred and that the grains contain numerous intragranular bubbles, dislocation loops or metallic precipitates associated with fission gas bubbles. On the contrary for the samples with burnups above $70 \mathrm{GWd} \cdot \mathrm{t}^{-1}$ and irradiated at temperatures below $1060^{\circ} \mathrm{C}$ the formation of small grains with sizes of about $250 \mathrm{~nm}$ is clearly seen. These grains do not contain visible defects and only some remaining small fission gas bubbles are observed. Even if most of the gas is initially swiped out from the re-structured grains, the continuous process of fission will produce fission gases which will start to cumulate in the small grains prior their release in the larger pores of the HBS. This can be observed on the image of the sample irradiated at $1000^{\circ} \mathrm{C}$ 
and $75 \mathrm{GWd} . \mathrm{t}^{-1}$ where small intragranular bubbles are visible. In addition string of bubbles precipitated at the grain boundaries are also observed in this later sample, whose connection can produce pathways for gas diffusion towards the intergranular pores. It should be noted that depending on the orientation of the grains towards the electron beam (diffraction conditions are limited in terms of tilting in the modified TEM) the bubbles are not always visible or the contrast is different. This is for example the case in the image of the sample irradiated at $82 \mathrm{GWd} \cdot \mathrm{t}^{-1}$ at $510^{\circ} \mathrm{C}$ where the bubbles can be seen as black dots, whereasin the preceding described sample they were visible both as white and black dots in adjacent grains, hence having different orientation towards the electron beam.

For the sample irradiated at very high burnup $\left(92 \mathrm{GWd} \cdot \mathrm{t}^{-1}\right)$ and at very high temperature $\left(1310^{\circ} \mathrm{C}\right)$ no re-structuring is observed. Rather a high concentration of dislocations is observed highlighting the plastic behaviour of the fuel at this temperature. Most of the defects produced at this temperature will also probably anneal reducing the facto the number of extended defects that can be involved in the formation of sub-boundaries by sequences of dislocation pinning-piling up-slight tilting of sub-grains.

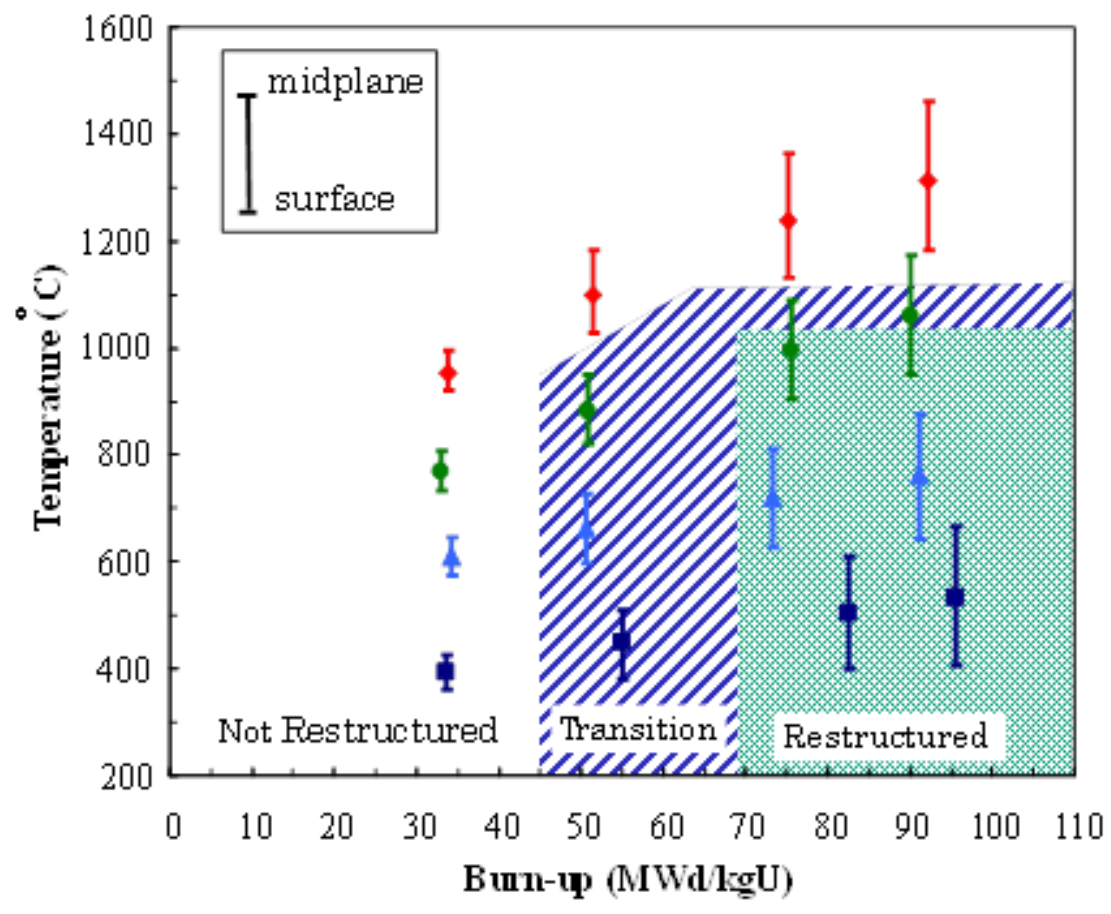

FIG. 6. Burnup and average irradiation temperature of the 16 stacks of the HBRP program ${ }^{2}$. The extremes represent the temperature difference between the surface and the centre of the discs, obtained by a finite element calculation ${ }^{2}$. The outer dark blue dashed area delineates the burnuptemperature range where re-structuring is partly achieved and the green the area where full restructuring is observed. 
Fig. 6 allows one to define the burnup and irradiation temperature threshold of the HBS formation: the burnup threshold is between 45 and $70 \mathrm{GWd} \cdot \mathrm{t}^{-1}$, and the temperature upper bound could be around $1100^{\circ} \mathrm{C}^{23}$. In the restructured specimen, polyhedral grains with size ranging between 0.5 and $2 \mu \mathrm{m}$ were observed away from the coarsened bubbles, while rounded grains in the size range 150$350 \mathrm{~nm}$ are only observed on the inner surface of coarsened bubbles, as shown in Fig. 3 . The size of polyhedral grains decreases as burnup increases. This can be explained by assuming that a homogeneous grain sub-division process takes place in the grains, forming smaller polyhedral grains. The formation of rounded grains might be due to the effect of free surfaces. This, in turn, would suggest that the HBS structure formation is independent from the existence of pores.

A recent observation of a sample with very high local burnup ( $\left.200 \mathrm{GWd} \cdot \mathrm{t}^{-1}\right)$ has shown evidence for a threshold upper bound in size of the newly formed grains at about $100 \mathrm{~nm}$, depicted in Fig. 7.
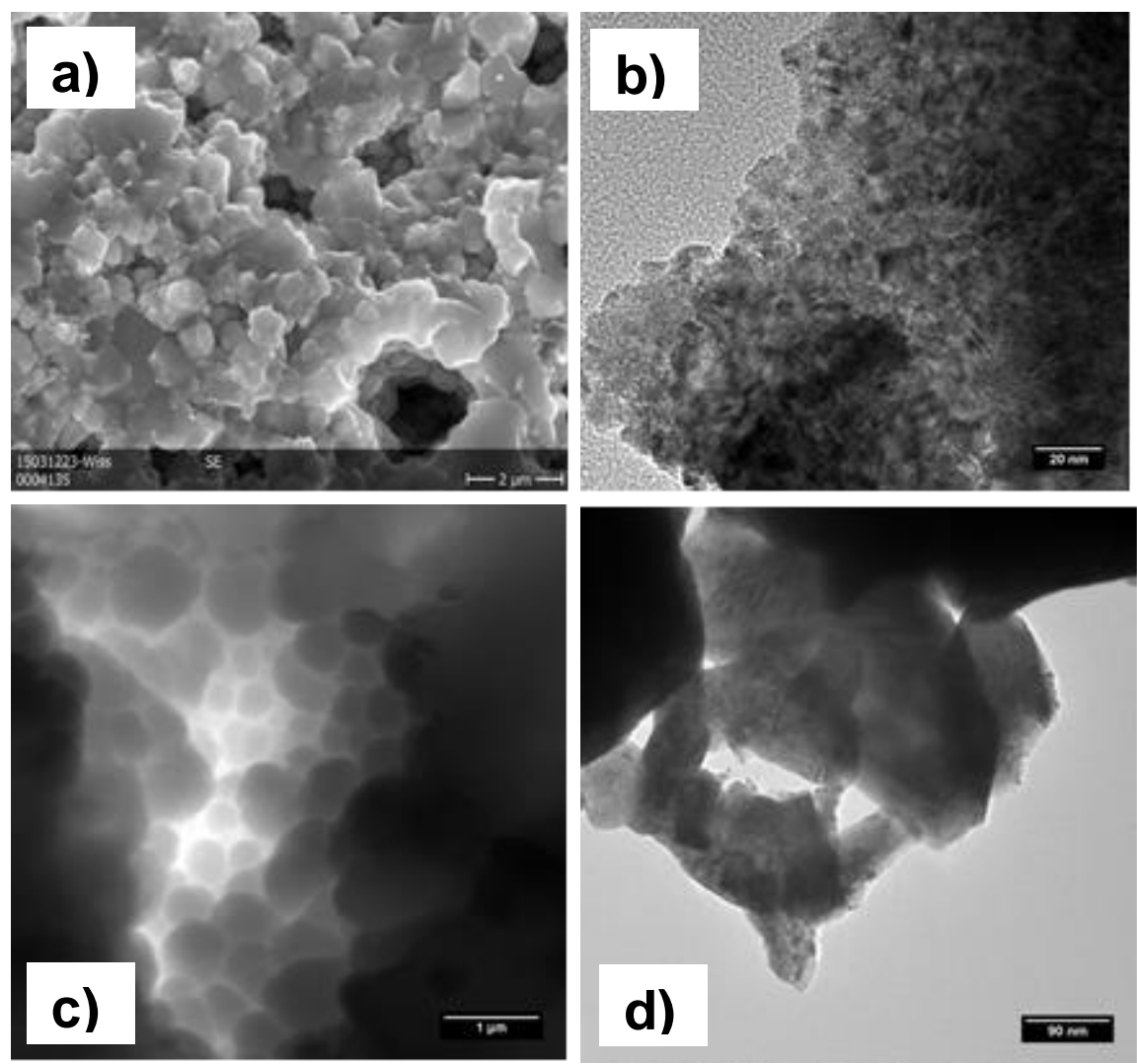

FIG 7.a) SEM image of a RIM sample with $200 \mathrm{GWd} \cdot \mathrm{t}^{-1}$ local burnup; b) TEM bright field micrograph showing a polygonised area; c) a STEM image revealing the nature of rounded restructured grains in HBS pores; and d) TEM bright field image showing subgrains of about $100 \mathrm{~nm}$ in size.

It could be shown that polyhedral grains forming in the bulk have sizes of about $100 \mathrm{~nm}$ as evidenced in the images of Fig. $7 \mathrm{a}$ and $7 \mathrm{~d}$ whereas the rounded grains in the pores have a fractal aspect as shown in the TEM and STEM images of Fig. $7 b$ and $7 c$ respectively. 
In addition to the characteristic grain restructuring and porosity development in the HBS one of the main question concerns the fate of the fission gas. Mogensen et al. ${ }^{24}$ determined the radial xenon concentration profiles by X-ray fluorescence (XRF) and EPMA of commercial low-enriched BWR fuel with burnups of 44.8-54.9 GWd. $\mathrm{t}^{-1}$ and high-enriched PWR fuel with burnups from 62.5 to 83.1 $\mathrm{GWd} . \mathrm{t}^{-1}$. They found that the percentage of gas released from the $\mathrm{UO}_{2}$ grains in the outer region of the fuel was generally small compared with the percentage released from the pellet cross-section. This is consistent with the current understanding that most of the fission gas released from the fuel when the high burnup structure forms is retained in the new pore structure. This has been also confirmed by Spino ${ }^{3,25-27}$ who showed that at least up to $250 \mathrm{GWd} \cdot \mathrm{t}^{-1}$ local burnup and $25 \%$ local porosity no relevant interconnecting paths between pores were present in the HBS as well as by Knudsen cell fission product release measurements ${ }^{9}$. Electron probe microanalysis was used in ITU to estimate the radial extent of the transformation of the microstructure by measuring the distance from the pellet edge over which Xe depletion in the fuel matrix occurs. In Fig. 8 the local Xe concentration measured in the outer regions of $\mathrm{UO}_{2}$ fuel sections is plotted as a function of the local burnup. The steep fall of the Xe concentration at burnup around $60 \mathrm{GWd} \cdot \mathrm{t}^{-1}$ marks the onset of the recrystallisation process. At burnups over $120 \mathrm{GWd} \cdot \mathrm{t}^{-1}$ the constant low Xe concentration indicates that the fuel microstructure transformation is complete.

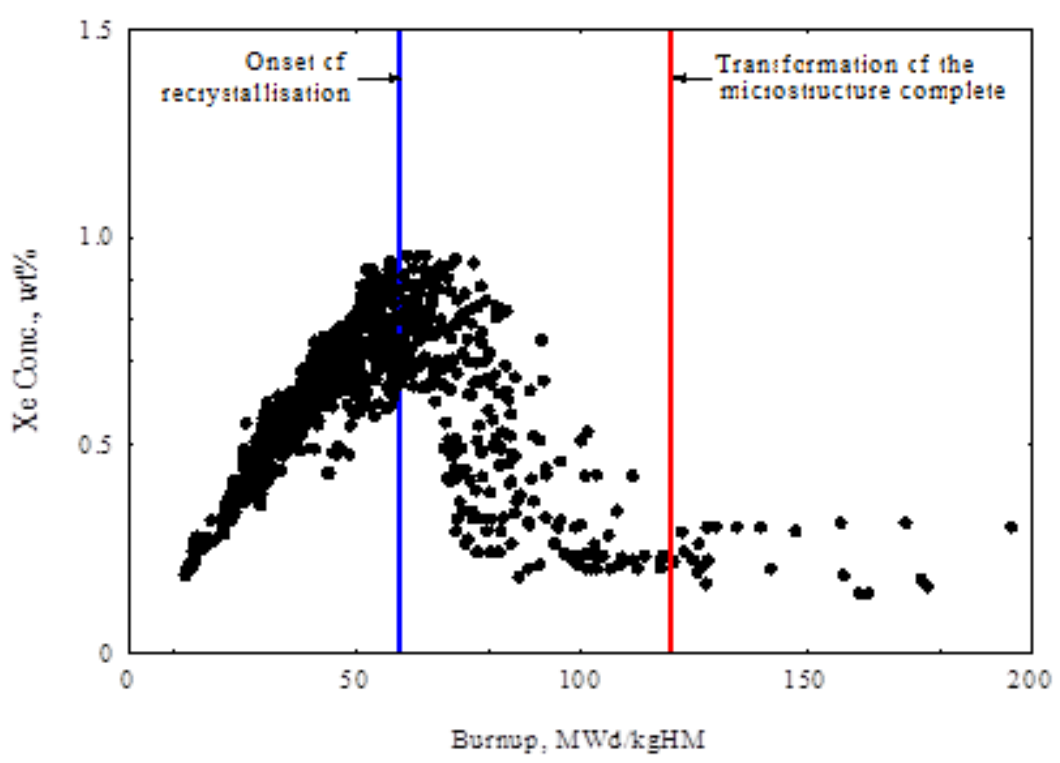

FIG. 8. EPMA results for the local concentration of xenon in the outer region of $\mathrm{UO}_{2}$ fuel related to the local burnup. The peak concentration at 60 to $75 \mathrm{GWd} \cdot \mathrm{t}^{-1}$ marks the burnup threshold for the formation of the high burnup structure

Using SIMS ${ }^{28}$ it has been confirmed that the fission gas lost from the matrix is contained in the pores of the high burnup structure (Fig. 9) and that little gas, if any, is released to the rod free volume 
either when recrystallisation occurs, or with increase in burnup above the threshold value once the high burnup structure is established (Fig. 10).

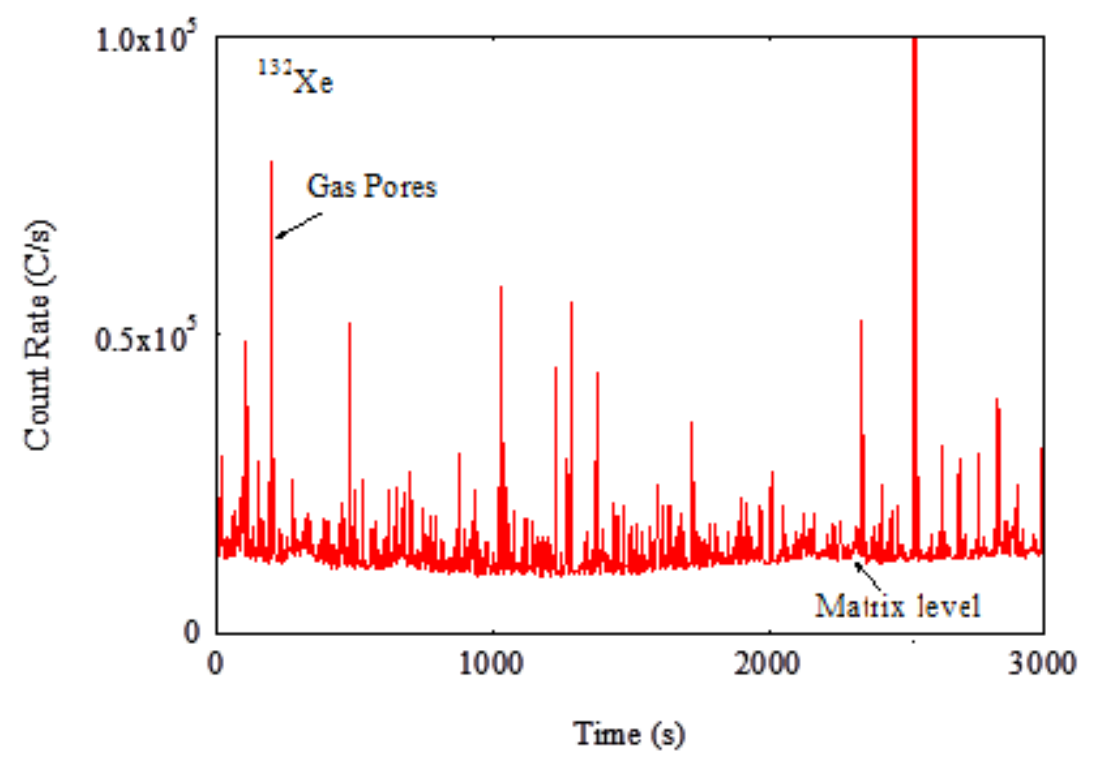

FIG. 9: SIMS depth profile for ${ }^{132} \mathrm{Xe}$ in the high burnup structure produced with a primary ion beam at a high current density of $154 \mathrm{~mA} \cdot \mathrm{cm}^{-2}$. The spikes are caused by the expulsion of gas from the pores in the microstructure. Time is equivalent to erosion depth. 


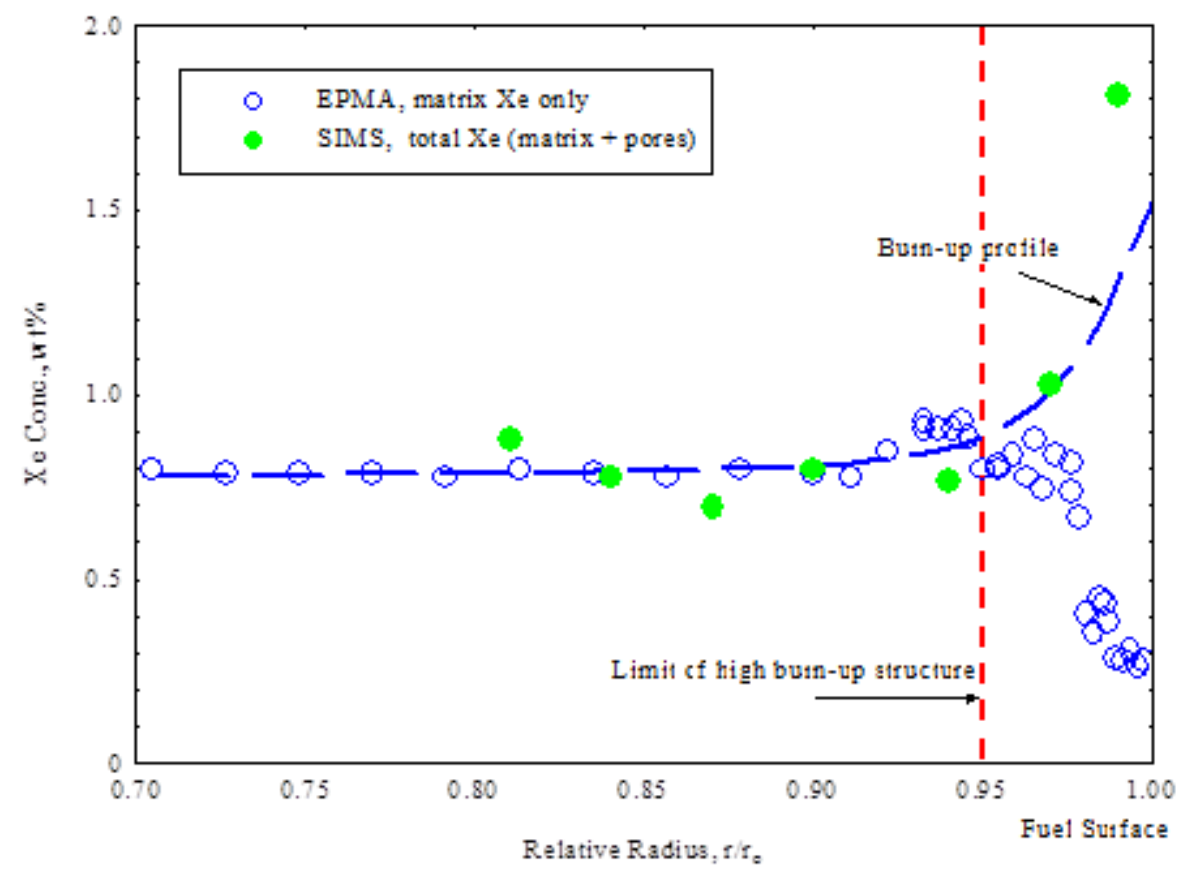

FIG. 10. The local concentration of retained xenon in the outer region of $\mathrm{UO}_{2}$ fuel as measured by SIMS and EPMA. The steep increase in the SIMS profile at the fuel surface indicates that almost all the gas missing from the $\mathrm{UO}_{2}$ matrix is contained in the pores of the high burnup structure. Note that in the interval between $r / r o=0.80$ and 0.95 , the gas is present as an atomic dispersion.

An important question with implications for the behaviour of the high burnup structure during a reactor accident is the pressure of the gas in the pores. The Xe intensity spikes in the SIMS depth profile in Fig. 9 can be converted to concentration using the matrix intensity level which is known from EPMA to correspond to about $0.25 \mathrm{wt} \%$. Knowing the size distribution of the pores in the high burnup structure, the gas pressure can then be estimated from the Xe concentration using a hard sphere equation of state ${ }^{28}$. With this method the average pressure of the gas in the pores was found to be about $45 \mathrm{MPa}$. Thus, the pores of the high burnup structure are overpressurised, but generally not excessively so. Consequently, it would appear that few of the pores present in the high burnup structure are sufficiently overpressurised to initiate fragmentation of the fuel during a reactor accident as could be experimentally observed during a laboratory high temperature annealing of a very high burnup sample ${ }^{9}$.

\section{GAS RELEASE}


Fission gas release from the fuel pellet, hence excessive internal pressurization of the fuel rod, could lead to a reduction of the thermal contact between fuel and cladding, thus increasing the fuel temperature. This may ultimately lead to fuel rod failure in the case of accidental transients. Originally it was feared that the formation of the HBS could lead to a slight increase in the oxygen

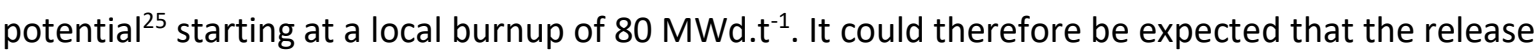
of the fission gases could be enhanced. However, as previously reported ${ }^{25,29,30}$ the LWR fuel remains stoichiometric or slightly hypostoichiometric. It was also thought that the HBS porosity would induce an enhanced mobility of the fission gases during normal conditions and that there was a new source for fission gas release occurring directly from the restructuring at high burnup.

The release of fission gas is in fact strongly affected by the irradiation temperature. During normal operating conditions LWR fuel experiences temperatures between $\sim 1300-1500 \mathrm{~K}$ at the pellet centre and $\sim 600-800 \mathrm{~K}$ at the rim. Measurements of fission gas release both in-pile and after fuel rod discharge do indicate an increase of the fraction of gas released with increasing burnup. For instance, post-irradiation examination data from rod puncturing tests reported by Manzel and Walker ${ }^{31}$ indicate fission gas release between $5-10 \%$ at an average burnup of $50 \mathrm{GWd} \cdot \mathrm{t}^{-1}$, and up to almost $25 \%$ for fuel with a very high average burnup of $100 \mathrm{GWd}^{-1}$. The exact radial location in $\mathrm{UO}_{2}$ fuel pellets and the mechanisms responsible for fission gas release at high burnup are not yet fully understood. However, it is now generally agreed that this release does not originate from the HBS, but rather from higher temperature regions towards the axial center of the fuel pellet, where temperature effects allow interconnection among intergranular fission gas bubbles and the opening of pathways for fission gas release along the grain boundaries. Both special irradiation ${ }^{2,32}$ and commercial fuel data ${ }^{14,26}$ indicate that almost all locally generated fission gas is retained in the intergranular HBS porosity.

In addition to the analyses of fission gas by EPMA and SIMS some thermal desorption analyses were performed using a Knudsen cell device ${ }^{33}$. Fig. 11 shows the normalized fractional release of Krypton during a Knudsen cell effusion test on very high burnup specimens (90-96 GWd.t ${ }^{-1}$ ). In this graph it appears clearly that the release of krypton is associated to the irradiation temperature and hence, since the burnup is very high, to the microstructure of the fuel. Although the onset for release is similar for the five samples, irradiated at the (almost) same burnup but at different temperatures, the normalized fractional release profile is very sharp for the restructured samples, contrariwise to those irradiated at temperatures where restructuring does not occur (above $1100^{\circ} \mathrm{C}$ ).

The quantity of gas released from the HBS was shown to correspond to the theoretical inventory and therefore that the restructuring process does not cause the release of the fission gas out of the fuel pellet which is clearly a positive feature of the HBS. 


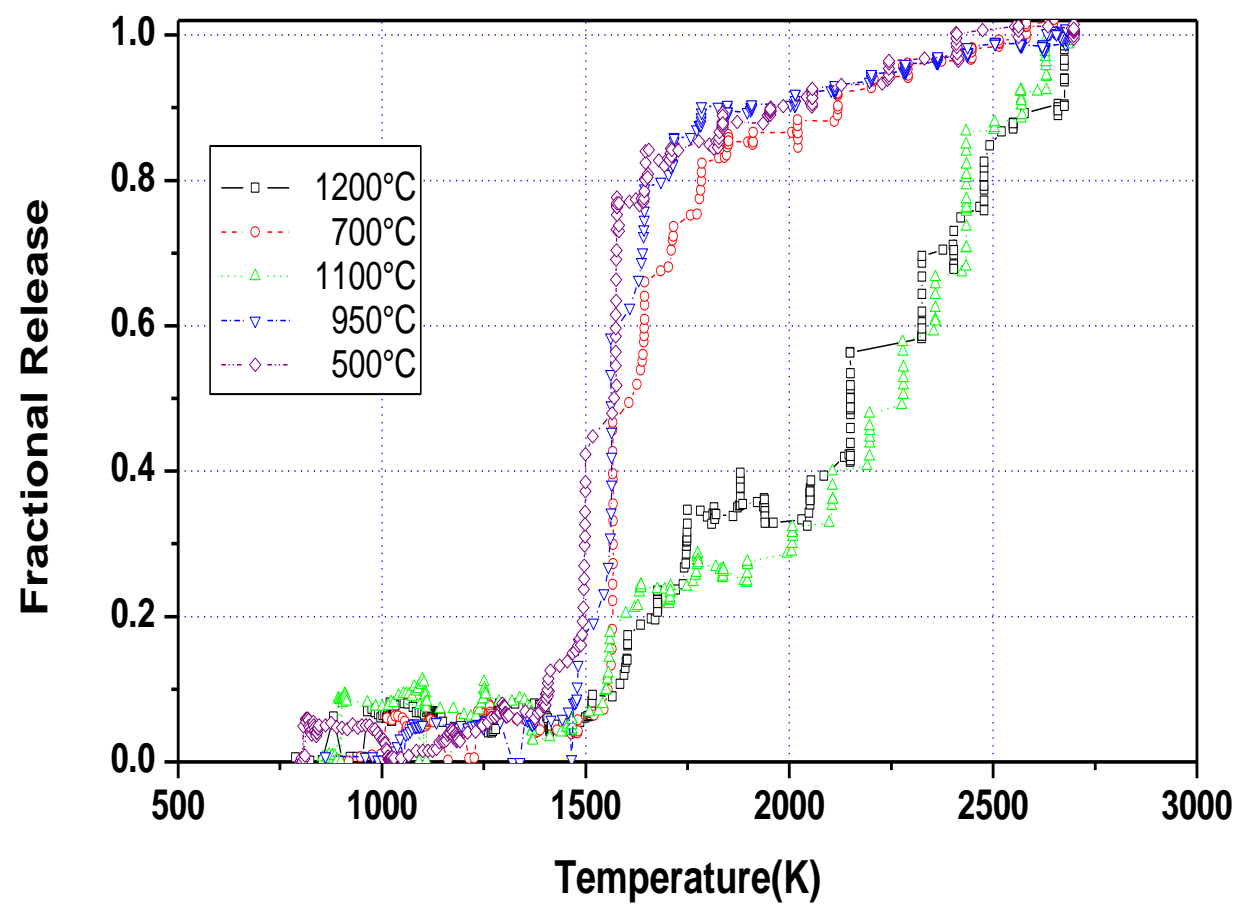

FIG. 11. ${ }^{85} \mathrm{Kr}$ normalized fractional release from $\mathrm{UO}_{2}$ samples (HBRP program ${ }^{2}$ ) irradiated in the $\mathrm{BU}$ range $90-96 \mathrm{GWd} \cdot \mathrm{t}^{-1}$ at various temperatures.

\section{THERMO-PHYSICAL PROPERTIES}

In fuel performance codes, the effect of the HBS on the heat transfer is generally included in the correlations describing the thermal conductivity degradation with burnup ${ }^{34}$. The modelling of the heat transfer includes the porosity build up in the HBS as well as in an improved gap conductance in order to account for the bonding layer between the ceramic pellets and the metallic cladding. To this end, for example, the cladding and pellet roughness is empirically reduced above a certain burnup to account for the filling up by mainly zirconium oxide, which has a higher thermal conductivity than that of the mixture of $\mathrm{He}$ and $\mathrm{Xe}$ in the residual gap. The thermal conductivity of the fuel decreases as burnup increases, but a partial thermal conductivity restoration is considered when the HBS is created $^{34}$. In this way account is made for the "cleaning" of the matrix from point defects and volatile fission products resulting from the reduced grains size. Some models link the thermal conductivity evolution to the variation of the lattice parameter, described in an empirical way ${ }^{35}$. The latter approach seems to be in line with complementary experimental data ${ }^{34}$.

The thermal diffusivity and the heat capacity of irradiated high burnup $\mathrm{UO}_{2}$ fuels were measured, and laboratory thermal annealing cycles with increasing maximum temperatures were applied to 
examine recovery effects ${ }^{34}$. The most conspicuous decrease in diffusivity was observed in high burnup samples subjected to in-pile temperatures of $600 \mathrm{~K}-800 \mathrm{~K}$. These samples showed a decrease in conductivity of up to a factor of four compared to fresh fuel. Analysis of the experimental measurements shows that the effective decrease of the thermal conductivity during reactor irradiation is due to: a) atomically dispersed fission products, b) irradiation and selfirradiation defects, c) fission gas and volatile fission products dynamically frozen in the fuel during irradiation, d) fission gas precipitation and porosity evolution.

The important effects due to fission gas were interpreted by considering the possible states, from gas-in-solid through bubble precipitation until intergranular swelling conditions. Thermal annealing leads to defect annihilation, and to healing of the lattice with a consequent recovery of thermal diffusivity.

The formation of the HBS has a positive effect by limiting the decrease in thermal conductivity with burnup. The effect of this restructuring, which entails a significant decrease in the fission gas concentration dynamically dissolved in the matrix, can be clearly seen in the graphs: the thermal conductivity at EOL, plotted in Fig. 12 as a function of burnup for different irradiation temperature2, shows that the formation of the HBS has a positive effect on the lattice thermal conductivity (i.e., if the trivial diminution due to fission-gas swelling is not taken into account).

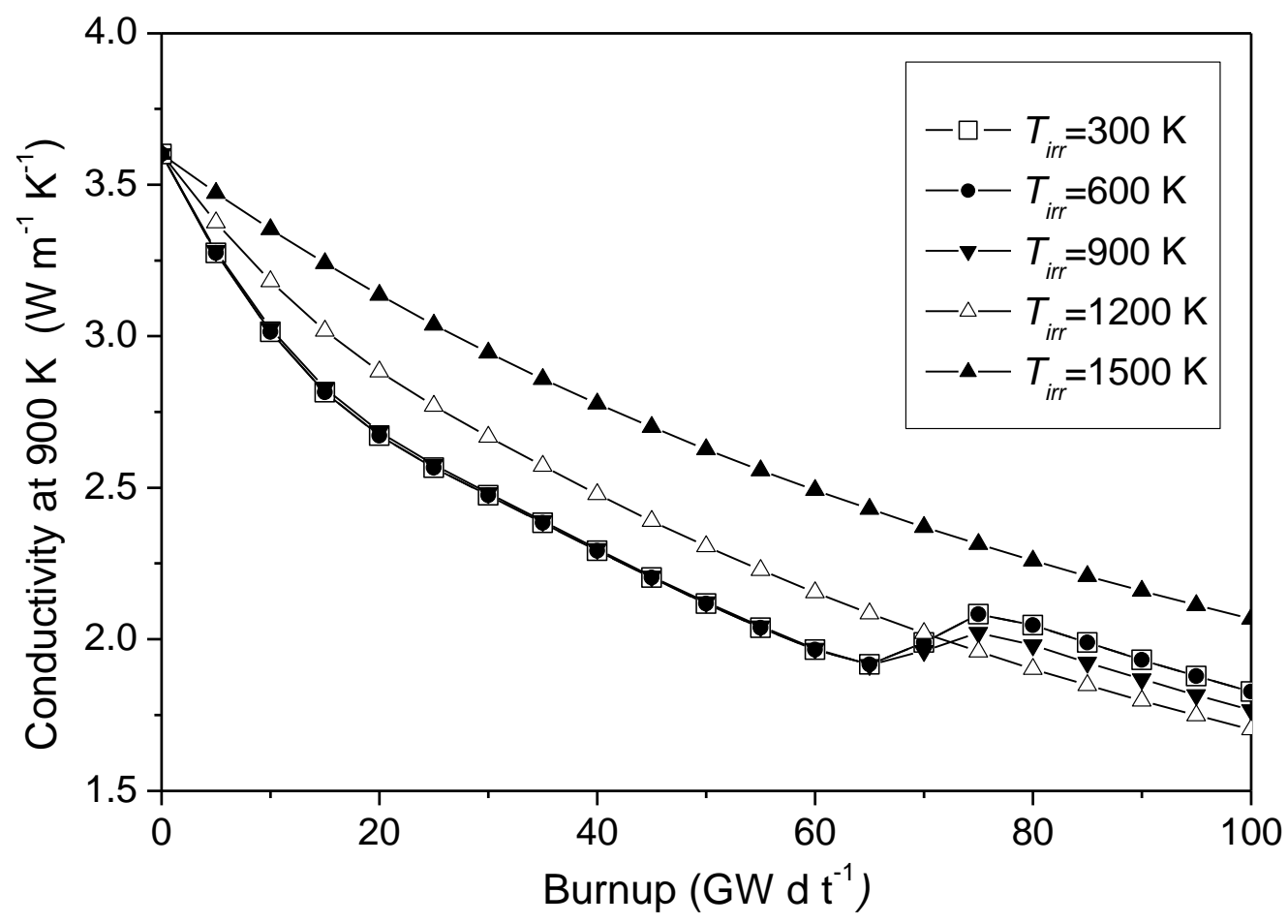

FIG. 12. Lattice thermal conductivity at EOL as a function of burnup for different irradiation temperatures.

Fig. 13 shows the evolution with burnup of the conductivity measured at $900 \mathrm{~K}$, for different irradiation temperatures, normalised to $5 \%$ porosity. It can be seen that the samples displaying the HBS have higher lattice conductivity than those irradiated at about $1200 \mathrm{~K}$, a temperature at which 
the HBS is not formed. One can see that only in samples irradiated at Tirr $>1500 \mathrm{~K}$ does the lattice conductivity become higher than that measured in the HBS.

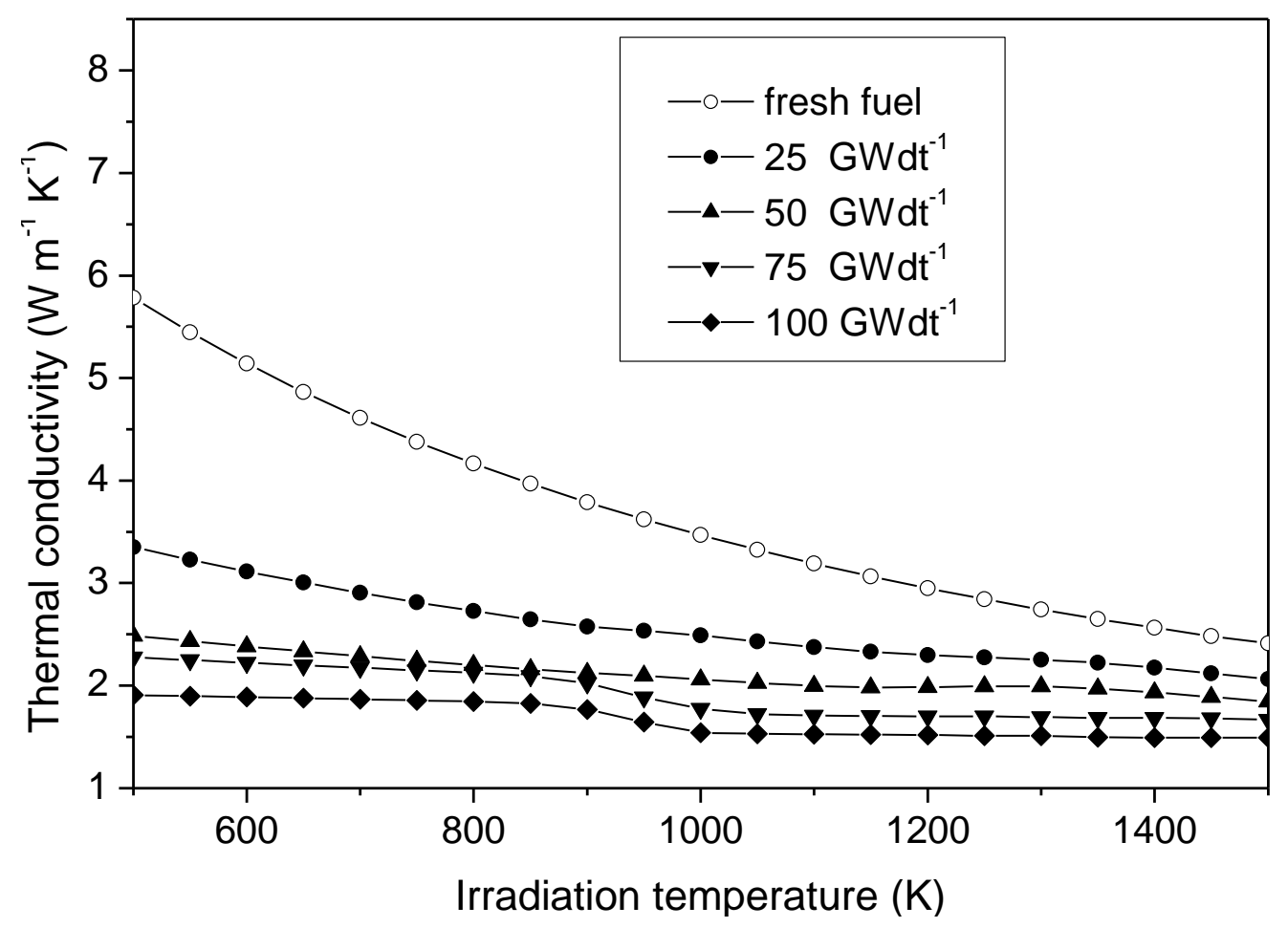

FIG. 13. Evolution of the conductivity (measured at $900 \mathrm{~K}$ ) with burnup, parametrically for different irradiation temperatures and normalised to $5 \%$ porosity.

In spite of the formation of the high burnup structure, the thermal diffusivity of the fuel at $100 \mathrm{MWd} . \mathrm{t}^{-1}$ was $55 \%$ higher than the value expected to result from the degradation caused by the build-up of fission products and point defects in the fuel lattice at this burnup. Clearly, the higher thermal diffusivity and conductivity caused by the HBS formation is a consequence of the removal of fission product atoms from the fuel lattice and healing of radiation defects that accompanies restructuring of the fuel grains (part of the HBS formation mechanisms). This effect is clearly observed in TEM investigation showing that at a nanometer size scale there are very few intragranular defects (see Fig. 5). Moreover, the role of the pores of the high burnup structure as sinks for the fission gas expelled from the fuel lattice during restructuring is more important than the counteracting effect as barriers to heat transport. With the increase of burnup, large stresses are produced in the matrix during laboratory annealing with sudden development of cracks. The higher is the fuel burnup, the lower the temperature at which these processes are activated. At $100 \mathrm{GWd} \cdot \mathrm{t}^{-1}$ the fuel fragments at temperatures just above the in-pile temperature. Therefore, a prediction of the thermal transport performance of the outer pellet region of high burnup fuel (which exhibit the HBS) under transient conditions is still uncertain, and further measurements must be conducted where the thermal diffusivity is measured under restrained conditions. 


\section{THERMO-MECHANICAL}

The effect of the long irradiation time in the mechanical analysis by means of fuel performance codes is mostly addressed to investigate cladding properties. In fuel, on the other hand, the thermomechanical properties basically observed are a reduction of the micro-hardness (Fig. 14) and and of the Young's modulus in high burnup fuel pellets. Fig 15. shows the variation of the Young's modulus in the burnup range 0-100 GWd. $\mathrm{t}^{-1}$ as experimentally determined by Laux et al. ${ }^{36}$ by measuring fresh uranium dioxide fuel, chemical analogues of irradiated fuel ${ }^{37}$ and special irradiation disks ${ }^{2}$ via high frequency acoustic microscopy. These data are compared to the local elastic modulus of a $67 \mathrm{GWd}$.t ${ }^{1}$ burnup $\mathrm{UO}_{2}$ pellet by Marchetti and co-workers ${ }^{38}$. The Young's modulus at $100 \mathrm{GWd} \cdot \mathrm{t}^{-1}$ decreases about 30\% with respect to the fresh fuel. This effect is dominated by the volume increase during the irradiation which causes in turn a porosity increase, an accumulation of fission products, and a dilatation of the crystal lattice ${ }^{39}$. The variation of the Young's modulus with burnup has been included in the fuel performance codes. This also holds for the bond between pellet and cladding. On the one hand, this structure improves the pellet-cladding interaction resistance since it is much softer than $\mathrm{UO}_{2}$. On the other hand, the pellet-clad bonding would make the cladding subjected to a bi-axial stress state due to pellet stack elongation. This bi-axial stress state is a mechanically more tough condition for cladding. 


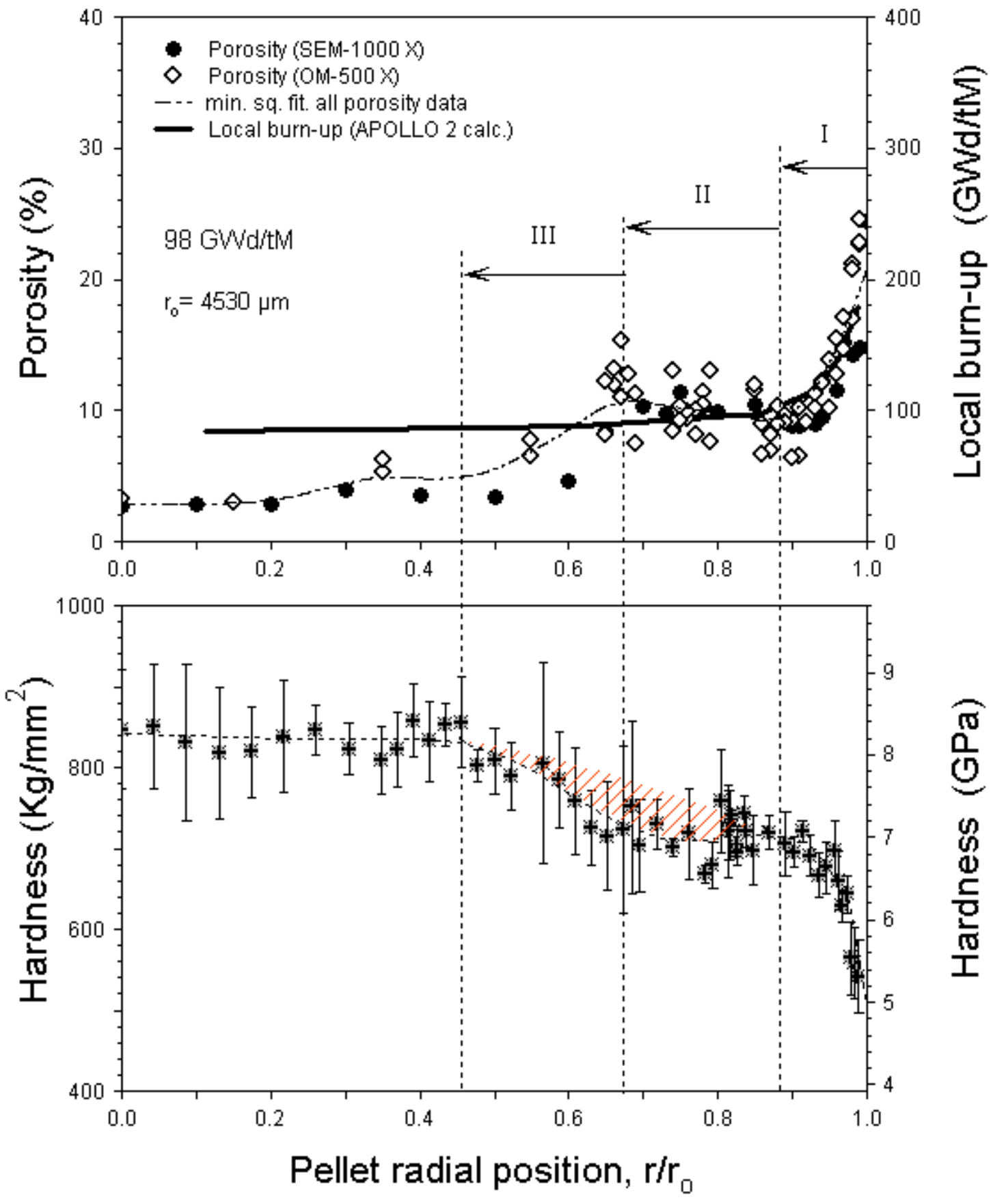

FIG. 14. Experimental values for micro-hardness of irradiated $\mathrm{UO}_{2}$ fuel with a burnup of $98 \mathrm{GWd} . \mathrm{t}^{-1}$ 


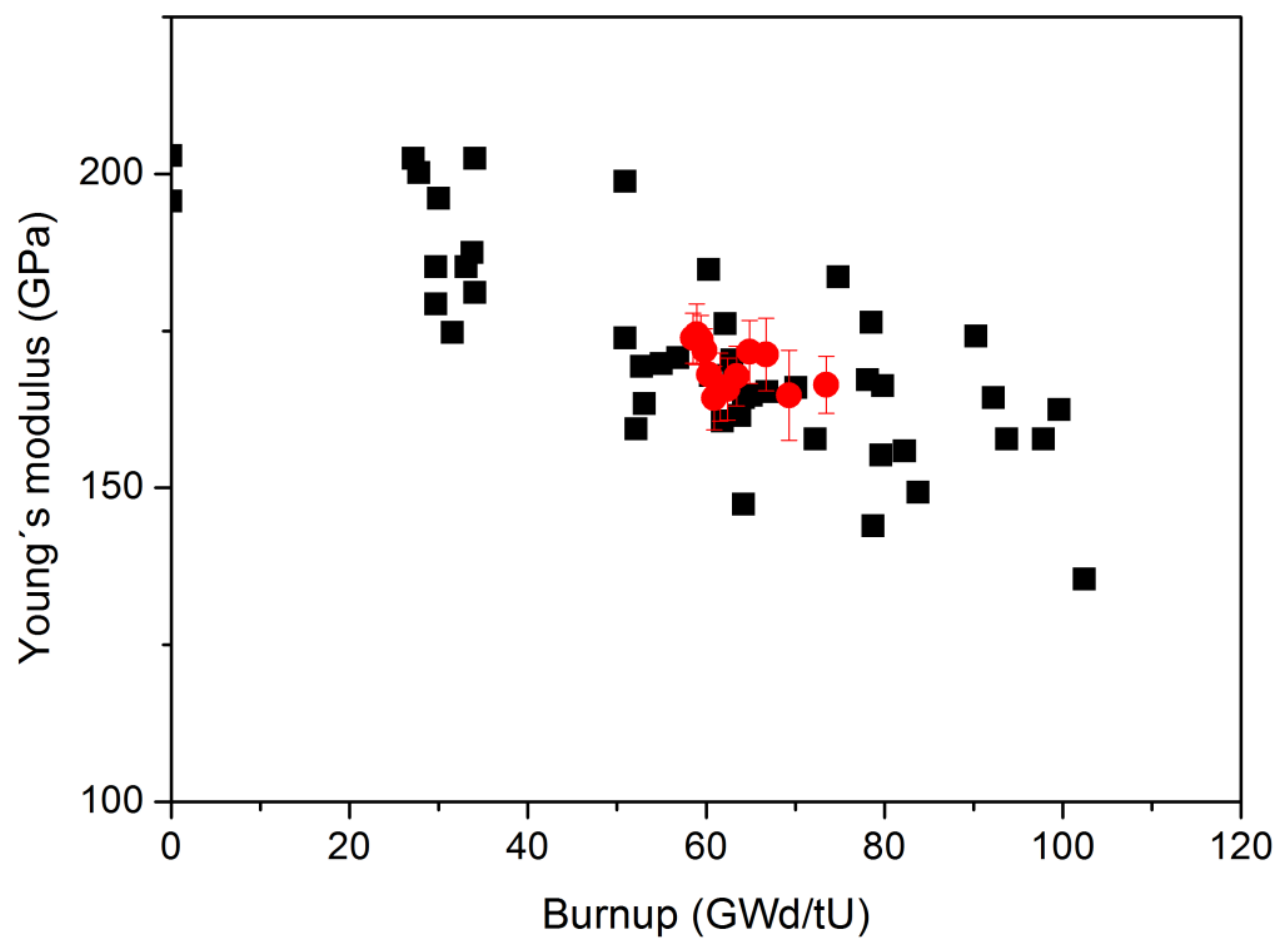

FIG. 15. Experimental Young's modulus of irradiated LWR fuels as a function of burnup ${ }^{36,38}$

\section{MODELLING OF FISSION GAS BEHAVIOUR}

The first simple model for the HBS formation in oxide fuels that was implemented in the TRANSURANUS $\operatorname{code}^{40}$ was proposed by Lassmann and relied on the local burnup value alone. More precisely, above a certain local burnup threshold, the HBS formation was assumed to start, resulting in the reduction of the fission product concentration in the matrix, concomitant with the formation of large HBS pores. Above a second burnup threshold, the HBS was assumed to be saturated, leading to a release of any additional gas arriving at the HBS pores. This second assumption has been questioned, since more recent analysis showed that the HBS pores remain closed up until local volume swelling values of $25 \%$ and negligible release was observed from the HBS during normal operating conditions.

The open questions about the HBS formation mechanisms and properties triggered new experimental campaigns, largely based on disc irradiations in order to assess the separate effect of the local temperature and burnup. The results revealed that the HBS formation only takes place below a certain temperature limit, which is attributed to defect healing. Therefore Khvostov et al. ${ }^{41}$ proposed a so-called effective burnup, which accounts for the fact that when the temperature exceeds a certain limit defect annealing will prevent further accumulation of the effective local 
burnup that is used for predicting the onset of the HBS formation. A recent critical re-analysis of published and new data along with a multi-scale and multi-physics simulation provided lead to the suggestion of a new temperature dependent effective burnup:

$$
\Delta b u_{e f f}=\left\{\begin{array}{c}
\Delta b u, T \leq T_{\text {thres }} \\
0, T>T_{\text {thres }}
\end{array}\right.
$$

where $\mathrm{T}$ is the local fuel temperature expressed in ${ }^{\circ} \mathrm{C}, \Delta b u$ is the considered burnup increment and $\mathrm{T}_{\text {thres }}$ is the temperature threshold in ${ }^{\circ} \mathrm{C}$ for healing of defects.

At present, the swelling caused by the HBS pores is mostly modelled separately with a very simple linear or quadratic function of burnup, as depicted in Fig. 16).

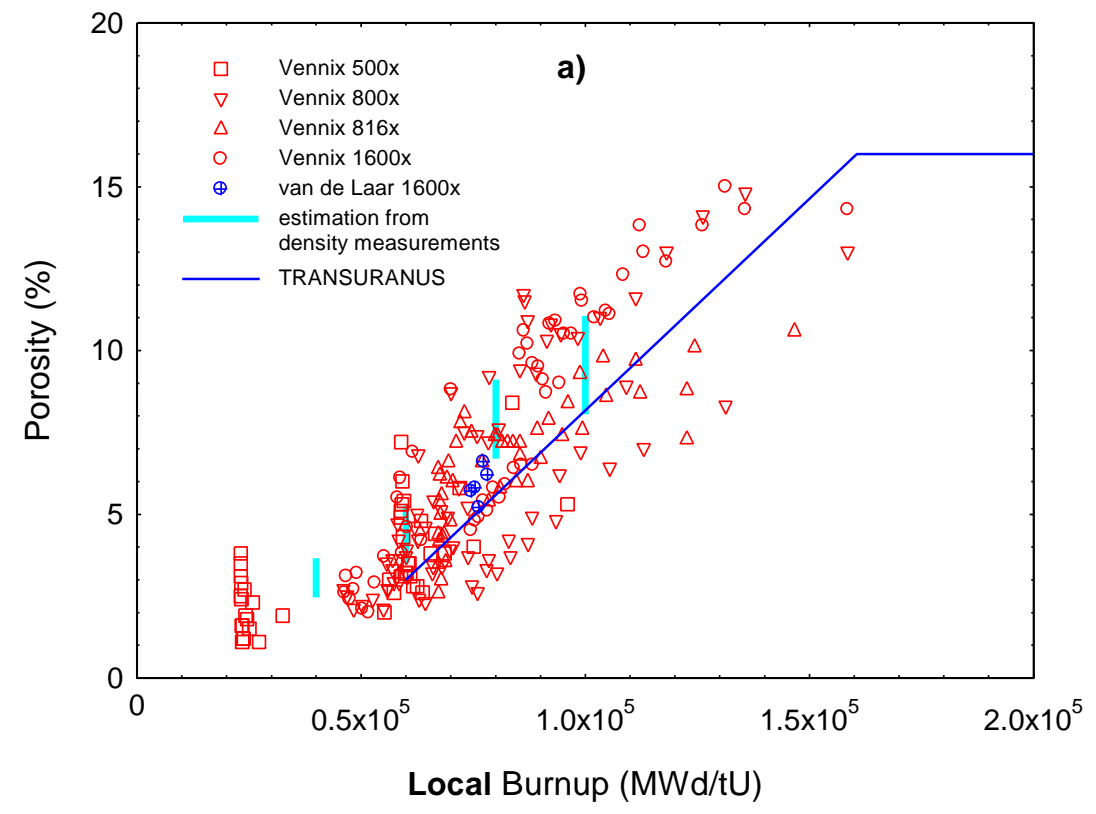

FIG. 16. Porosity as a function of the local burnup for highly irradiated fuel, and the corresponding correlation adopted in the TRANSURANUS code.

In order to provide a more detailed description of the HBS formation for future application in a fuel performance code, a first step was taken to describe the evolution of gas depletion and grain subdivision in a more consistent manner ${ }^{42}$. For this purpose, targeted grain-size measurements on samples showing incomplete restructuring were performed ${ }^{42}$. Based on the new experimental data, 
an exponential reduction of the average grain size with local effective burnup, paired with a simultaneous depletion of intra-granular fission gas driven by diffusion, was assumed. The model predictions are in satisfactory agreement with the EPMA results of intragranular gas concentration (Fig. 15). Two innovative points of the model are (i) the coupling of the grain size reduction with the intragranular fission gas behaviour on a physically sound basis, but with a degree of complexity suitable for applications in integral fuel performance codes, and (ii) the capability of predicting the HBS formation delay reported for large-grained fuels ${ }^{43}$. Modelling of the HBS porosity growth, to be coupled with the new model for the fission gas depletion, is currently undergoing.

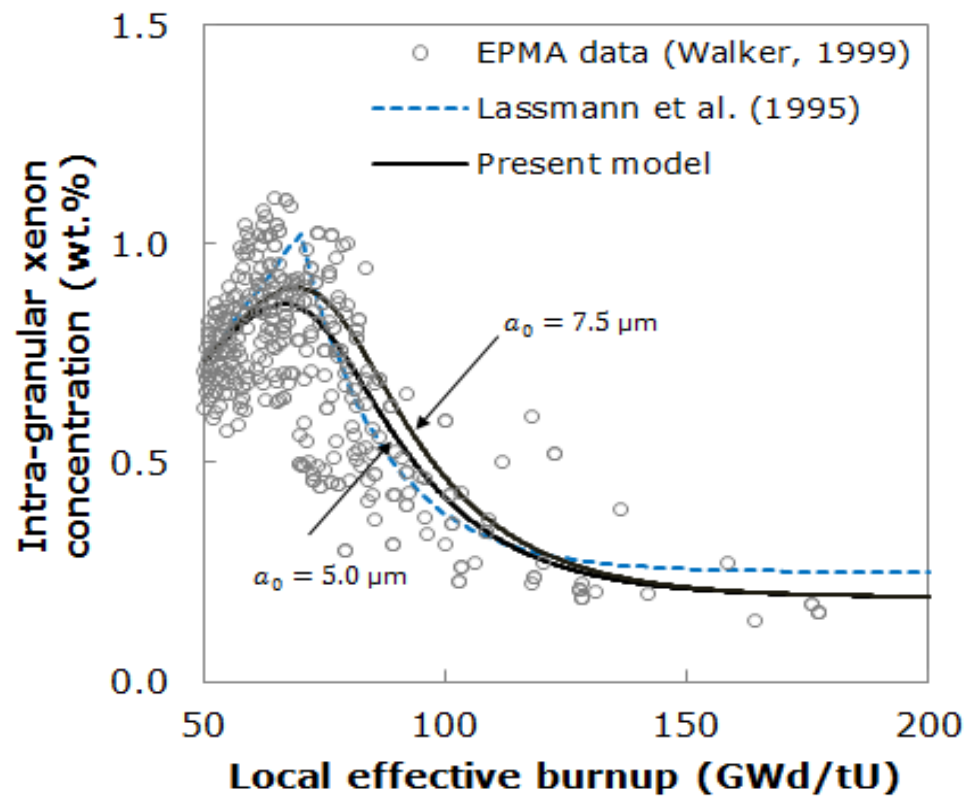

FIG. 17. The new model by Pizzocri et al. ${ }^{42}$ describes the fission gas depletion in the HBS. The model predicts a delay in the xenon depletion when assuming a bigger initial grain size $\left(\mathrm{a}_{0}\right)$. The model from Lassmann et al. ${ }^{44}$ is also shown for comparison.

Based on the new model for the HBS formation as a function of temperature and burnup, a new model for the release from this structure under design basis accident conditions is being developed, which depends on the local temperature levels, the effective burnup and should account for any constraint effect. It relies on local experimental data obtained from HBS samples in a Knudsen Cell that is coupled with a mass spectrometer ${ }^{33}$, as well as on the basis of integral results observed in fuel rod segments. The internal gas pressure, especially after a reactivity insertion accident, is remarkably enhanced by the burst release of fission gas following the grain separation, and is generally correlated with the peak fuel enthalpy. The fission gas originates mainly from the intergranular gas bubbles, even though some contribution comes from gas pores within the grains and the high burnup structure. Although few models consider the thermal diffusion process of fission gas atoms from inside the grains, it is generally considered that it can be substantially neglected. This is mostly explained by the short duration of the high temperature period of the pellet (e.g. a few or several 
tens of seconds) to allow for the thermal diffusion to contribute significantly to the fission gas release increase, even if the fuel pin runs into a departure from nucleated boiling phase. In the case of a loss of coolant accident, the time-interval is much longer and the mechanical constraint on the fuel - hence the HBS pores and grain boundary bubbles - is lower, causing a larger contribution to the internal gas pressure increase. The constraint effect must therefore be accounted for in the model describing the behaviour of the HBS pores during DBAs.

\section{CONCLUSIONS}

HBS is the self-reorganization of the fuel to respond to the radiation damage and harsh thermomechanical conditions established in-pile. It has been suspected since decades that the HBS implies fundamentally a degradation of the in-pile behaviour of nuclear fuel. For example, several campaigns have been undertaken to test possible routes (including fuel grain additives and special fabrication procedures) to delay or avoid the onset of the HBS formation, with the purpose of bounding or controlling a postulated enhanced fission gas release from restructured fuel during offnormal conditions (e.g. sudden temperature excursions), before clear experimental data supported these assumptions.

The acquisition of experimental data specifically targeted at assessing key properties and behavior of HBS has produced nowadays a widespread consensus on the main features and properties of the HBS structure. The technology concerns related to fission gas behavior, swelling and fuel-cladding mechanical interaction, and thermal conductivity of high burnup fuel under normal operating conditions have been positively addressed and today's LWR fuel operates to burnup levels which encompass the formation of HBS with no specific reported issues. The experimental data on HBS are incorporated in some fuel performance codes with good success ${ }^{32,40,41}$. All the models proposed converge and show evidence that the formation of the HBS is ultimately driven by and results in the minimization of the local internal energy of the system.

There are however still open questions concerning the mechanisms driving the HBS formation and its evolution during continued irradiation - data for $\mathrm{UO}_{2}$ fuel with a local burnup in the range 160$250 \mathrm{GWd} \cdot \mathrm{t}^{-1}$ have been already collected ${ }^{6,9,31}$. Further investigations, combining microstructural and microanalytical experimental studies using state of the art characterization tools (e.g. FIB, TEM and SIMS) and a multi-scale modelling approach will possibly provide answers to these questions.

\section{ACKNOWLEDGEMENTS}

The authors are indebted with many colleagues at ITU (impossible to mention all of them!) for all the work performed over almost 3 decades on the topic of the high burnup structure. Most of them will 
appear in the citations. The contribution by AREVA for supplying irradiated LWR fuel samples was essential, so as the important role played by the HBRP irradiation and examination programmes. 


\section{References}

(1) Belle, J. Uranium Dioxide: Properties and Nuclear Applications, United States Atomic Energy Commission, 1961.

(2) Kinoshita, M.; Sonoda, T.; Kitajima, S.; Sasahara, A.; Kameyama, T.; Matsumura, T.; Kolstad, E.; Rondinella, V. V.; Ronchi, C.; Hiernaut, J. P.; Wiss, T.; Kinnart, F.; Ejton, J.; Papaioannou, D.; Matzke, H. In 2004 International Meeting on LWR Fuel Performance; ANS: Orlando, FI, USA, 2004; Vol. paper 1102, p 207.

(3) Spino, J.; Baron, D.; Coquerelle, M.; Stalios, A. D. Journal of Nuclear Materials 1998, 256, 189.

(4) Sonoda, T.; Kameyama, T.; Sasahara, A.; Kitajima, S.; Nauchi, Y.; Kinoshita, M.; Rondinella, V. V.; Wiss, T.; Hiernaut, J. P.; Papaioannou, D.; Sheindlin, M.; Staicu, D. In American Nuclear Society - 2007 LWR Fuel Performance/Top Fuel 2007, p 340.

(5) Sonoda, T.; Kinoshita, M.; Ray, I. L. F.; Wiss, T.; Thiele, H.; Pellottiero, D.; Rondinella, V. V.; Matzke, H. Nuclear Instruments and Methods in Physics Research Section B: Beam Interactions with Materials and Atoms 2002, 191, 622.

(6) Walker, C. T.; Staicu, D.; Sheindlin, M.; Papaioannou, D.; Goll, W.; Sontheimer, F. Journal of Nuclear Materials 2006, 350, 19.

(7) Ray, I. L. F.; Thiele, H.; Matzke, H. J. Nucl. Mater. 1992, $188,90$.

(8) Noirot, J.; Desgranges, L.; Lamontagne, J. Journal of Nuclear Materials 2008, 372,

318.

(9) Hiernaut, J. P.; Wiss, T.; Colle, J. Y.; Thiele, H.; Walker, C. T.; Goll, W.; Konings, R. J. M. J. Nucl. Mater. 2008, 377, 313.

(10) Konings, R. J. M.; Wiss, T.; Guéneau, C. In The Chemistry of the Actinides and Transactinides Elements; fourth edition ed.; Morss, L. R., Edelstein, N. M., Fuger, J., Eds.; Springer: Dordrecht, 2010; Vol. 6, p 3665.

(11) Rondinella, V. V.; Wiss, T. Mat. Today 2010, 13, 24.

(12) Matzke, H.; Blank, H.; Coquerelle, M.; Lassmann, K.; Ray, I. L. F.; Ronchi, C.; Walker, C. T. J. Nucl. Mater. 1989, 166, 165.

(13) Matzke, H. Radiation Effects 1982, 64, 3.

(14) Spino, J.; Stalios, A. D.; Santa Cruz, H.; Baron, D. Journal of Nuclear Materials 2006, 354, 66.

(15) Capia, F., Technische Universität München, 2017.

(16) Rondinella, V. V.; Cappia, F.; Wiss, T.; Marchetti, M.; Papaioannou, D.; Bremier, S.; Nasyrow, R. In TOPFUEL Boise, ID, 2016, p 1593.

(17) Lozano, N.; Desgranges, L.; Aymes, D.; Niepce, J. C. J. Nucl. Mater., 1998, 257, 78.

(18) Une, K.; Nogita, K.; Kashibe, S.; Imamura, M. J. Nucl. Mater. 1992, 188, 65.

(19) Une, K.; Nogita, K.; Shiratori, T.; Hayashi, K. J. Nucl. Mater., 2001, 288, 20.

(20) Ray, I. L. F.; Matzke, H.; Thiele, H.; kinoshita, M. J. Nucl. Mater., 1997, 245, 115.

(21) Wiss, T.; Thiele, H.; Janssen, A.; Papaioannou, D.; Rondinella, V. V.; Konings, R. J. M. JOM 2013, 64, 1390.

(22) Nogita, K.; Une, K. Nucl. Instrum. Meth. B 1994, B91, 301.

(23) Holt, L.; Schubert, A.; Van Uffelen, P.; Walker, C. T.; Fridman, E.; Sonoda, T. Journal of Nuclear Materials 2014, 452, 166.

(24) Mogensen, M.; Pearce, J.; Walker, C. T. J. Nucl. Mater. 1999, 264, 99.

(25) Spino, J.; Peerani, P. Journal of Nuclear Materials 2008, 375, 8.

(26) Spino, J.; Papaioannou, D.; Glatz, J. P. Journal of Nuclear Materials 2004, 328, 67.

(27) Spino, J.; Rest, J.; Goll, W.; Walker, C. T. Journal of Nuclear Materials 2005, 346, 131.

(28) Walker, C. T.; Bremier, S.; Portier, S.; Hasnaoui, R.; Goll, W. J. Nucl. Mater. 2009, 393, 
(29) Kleykamp, H. Journal of Nuclear Materials 1979, 84, 109.

(30) Walker, C. T.; Rondinella, V. V.; Papaioannou, D.; Winckel, S. V.; Goll, W.; Manzel, R. Journal of Nuclear Materials 2005, 345, 192.

(31) Manzel, R.; Walker, C. T. Journal of Nuclear Materials 2002, 301, 170.

(32) Van Uffelen, P.; Konings, R. J. M.; Vitanza, C.; Tulenko, J. In Handbook of nuclear engineering; Cacuci, D. G., Ed.; Springer: 2010, p 1519.

(33) Colle, J. Y.; Maugeri, E.; Thiriet, C.; Talip, Z.; Capone, F.; Hiernaut, J. P.; Konings, R. J. M.; Wiss, T. J. Nucl. Sci. tech. 2014, 51, 700.

(34) Ronchi, C.; sheindlin, M.; Staicu, D.; Kinoshita, M. J. Nucl. Mater. 2004, 327, 58.

(35) Baron, D. In Seminar on Thermal Perf. of High Burn-up LWR Fuel; OECD/NEA:

Cadarache, France, 1998, p 129.

(36) Laux, D.; de Weerd, W.; Papaioannou, D.; Kitajima, S.; Rondinella, V. V.; Despaux, G. Progress in Nuclear Energy 2014, 72, 63.

(37) Lucuta, P. G.; Verrall, R. A.; Matzke, H.; Balmer, B. J. Journal of Nuclear Materials $1991,178,48$.

(38) Marchetti, M.; Laux, D.; Cappia, F.; Laurie, M.; Van Uffelen, P.; Rondinella, V. V.; Wiss, T.; Despaux, G. IEEE Transactions on Nuclear Science 2016, 63, 1520.

(39) Spino, J.; Papaioannou, D. Journal of Nuclear Materials 2000, 281, 146.

(40) Lassmann, K. In Nuclear Materials for Fission Reactors; Schumacher, H. M., Ed.; Elsevier: Oxford, 1992, p 295.

(41) Khvostov, G.; Mikityuk, K.; Zimmermann, M. A. Nuclear Engineering and Design 2011, 241, 2983.

(42) Pizzocri, D.; Cappia, F.; Luzzi, L.; Pastore, G.; Rondinella, V. V.; Van Uffelen, P. Journal of Nuclear Materials 2017, 487, 23.

(43) Noirot, J.; Pontillon, Y.; Yagnik, S.; Turnbull, J. A. Journal of Nuclear Materials 2015, $462,77$.

(44) Lassmann, K.; Walker, C. T.; van de Laar, J.; Lindström, F. Journal of Nuclear Materials 1995, 226, 1. 